\title{
Web-based voorlichtingsfilm over mondzorg
}

Cariës is de meest voorkomende irreversibele aandoening bij kinderen in Nederland: van de 5-jarige kinderen heeft meer dan de helft een of meer gaatjes (gehad). De etiologie van cariës is grotendeels bekend, waardoor gerichte preventie kan worden toegepast. Het allerbelangrijkste van deze preventie betreft de zelfzorg. De adviezen die tot verbetering van deze zelfzorg moeten leiden, zijn echter niet bij iedereen bekend. TNO heeft in 2009 de voorlichtingsfilm 'Een gezond kindergebit' gemaakt, gericht op ouders van jonge kinderen.

Om te meten of het geven van voorlichting via een web-based film tot kennisvermeerdering leidt, is een pilotonderzoek uitgevoerd bij consultatiebureaus (CB's) in Zeeland. Ouders die op het CB kwamen, kregen een kaartje mee naar huis met daarop de link naar de website waarop de film kon worden bekeken. Voor en na het filmpje vulden de ouders een korte vragenlijst in.

De antwoorden op de vragen bij de voormeting waren mogelijk gerelateerd aan eigen ervaring. In de nameting leken deze antwoorden gebaseerd te zijn op toegenomen kennis door het zien van de film.

Als het veronderstelde modelingeffect daadwerkelijk optreedt - ouders gaan het gewenste gedrag vertonen doordat het in de film is voorgedaan - zijn deze resultaten veelbelovend. Dit zal worden onderzocht in een vervolgstudie die in 2011 van start is gegaan.

\section{Inleiding}

Cariës is de meest voorkomende irreversibele aandoening bij kinderen in Nederland: $56 \%$ van de 5 -jarigen heeft cariës; deze kinderen hebben gemiddeld 8 carieuze tandvlakken, waarvan slechts $17 \%$ behandeld is. ${ }^{1}$ Problemen aan het melkgebit hebben gevolgen voor functie (kauwen, bijten, spreken), esthetiek, pijn en kwaliteit van leven. Bovendien kunnen dergelijke problemen leiden tot angst voor de tandheelkundige behandeling. ${ }^{2}$ De etiologie van cariës is grotendeels bekend, waardoor gerichte preventie kan worden toegepast. Het Ivoren Kruis heeft preventieve adviezen opgesteld (zie kader). ${ }^{3}$

De maatschappelijke kosten van de mondzorg voor de jeugd zijn in 2008 berekend op 316 miljoen euro. ${ }^{4}$ Deze zorg wordt betaald uit het basispakket van de zorgverzekering. Berekeningen die zijn uitgevoerd op gegevens die TNO ter beschikking staan, laten zien dat als 5-jarigen dagelijks worden nagepoetst door ouders, jaarlijks een directe besparing (ziektekosten basispakket) kan worden bereikt van 1 tot 3 miljoen euro. Deze schatting is conservatief, omdat ze gebaseerd is op slechts 1 cohort 5-jarigen en de langetermijnbesparingen er niet in zijn meegenomen. De jeugdgezondheidszorg bereikt vrijwel alle kinderen in hun eerste levensjaar. Daarna neemt het bereik licht af. Gemeten aan de vaccinatiegraad bereikt de jeugdgezondheidszorg $95 \%$ van de kinderen. ${ }^{5}$ De jeugdgezondheidszorg is daardoor bij uitstek geschikt om voorlichting te geven over mondgezondheid aan de ouders van kleine kinderen. Voorlichting over mondgezondheid valt onder het maatwerkdeel van de jeugdgezondheidszorg en wordt dus niet standaard aan de jeugd aangeboden.
Advies Cariespreventie

- Beginnen met tandenpoetsen vanaf de doorbraak van het eerste tandje.

- Poetsen met fluoridetandpasta:

- Kinderen van o $t / m 1$ jaar: vanaf de doorbraak eenmaal per dag poetsen met fluoride-peutertandpasta (500-750 ppm F).

- Kinderen van 2, 3, en 4 jaar: tweemaal per dag poetsen met fluoride-peutertandpasta (500-750 ppm F).

- Kinderen van 5 jaar en ouder: tweemaal per dag poetsen met fluoridetandpasta voor volwassenen (1000-1500 ppm F). In de handel zijn ook tubes verkrijgbaar met het opschrift 'juniortandpasta'. Kijk dan altijd naar de leeftijd die hierbij wordt aangegeven.

- Na het poetsen niet met water spoelen; uitspugen van de tandpasta is voldoende.

- Voor alle leeftijden geldt: extra fluoridemaatregelen op indicatie.

- Napoetsen door een volwassene tot het kind 10 jaar is.

- Niet vaker eten of drinken dan maximaal zeven keer per dag.

- Vanaf 2-jarige leeftijd Een tandarts of mondhygiënist bezoeken.

Bron: Ivoren Kruis

Voorlichting over de manier waarop ouders het melkgebit van hun kind gezond kunnen houden, bijvoorbeeld door middel van folders, leidt over het algemeen tot enige kennistoename, zo blijkt uit de literatuur. ${ }^{6-9}$ Echter, Alsada e.a. rapporteerden een kennistoename van meer 
dan $30 \%$ wanneer de voorlichting via een dvd werd verstrekt. ${ }^{6}$ Daarom is een korte voorlichtingsfilm over mondgezondheid ontwikkeld, waarin de hiervoor beschreven adviezen voor het voetlicht worden gebracht. De film is web-based beschikbaar en toegankelijk via een link, die de consultatiebureaumedewerker aan de ouder verstrekt. Het bereik is in beginsel groot, doordat meer dan $90 \%$ van de Nederlandse huishoudens over internet beschikt.

Kennisoverdracht is een noodzakelijke voorwaarde voor het tot stand brengen van gewenst gedrag, maar is op zichzelf niet voldoende. Een groot bijkomend voordeel van voorlichting over mondgezondheid in de vorm van een film is dat het gewenste gedrag kan worden voorgedaan. Gussy wees erop dat het demonstreren van het gewenste gedrag het meest effectief is. ${ }^{8}$ Er wordt zodoende niet alleen kennis overgedragen, maar via het mechanisme van modeling kan het gewenste gedrag door ouders op correcte wijze worden geïmiteerd..$^{10}$ Bovendien is bekend dat modeling het vertrouwen versterkt in het eigen vermogen om het juiste gedrag te vertonen. ${ }^{11}$ Het doel van dit pilotonderzoek is te onderzoeken of een web-based voorlichtingsfilm het kennisniveau van ouders over een onderwerp uit het maatwerkdeel (i.c. mondgezondheid) kan doen toenemen. Als dat mogelijk blijkt, kan door middel van vervolgonderzoek worden vastgesteld of die kennis beklijft en of die leidt tot het gewenste gedrag.

Materiaal en methode

TNO heeft in 2009 de voorlichtingsfilm 'Een gezond kindergebit' gemaakt. In deze voorlichtingsfilm komen de adviezen zoals opgesteld door het Ivoren Kruis aan de orde. De film is bedoeld voor ouders van kinderen tot 5 jaar en kan via een website worden bekeken. De film is momenteel alleen in het Nederlands beschikbaar. GGD Zeeland was bereid om aan de pilotstudie mee te werken. Twee medewerkers van TNO bezochten de CB's van Goes, Sint-Maartensdijk, Sint Philipsland, Kapelle en Rilland. Aan 102 ouders/verzorgers die voor een consult op het consultatiebureau (CB) kwamen, werd gevraagd deel te nemen. Als zij met deelname instemden, ontvingen zij een enveloppe met daarin een korte vragenlijst die ter plekke werd ingevuld (voormeting), een kaartje met daarop de link naar de website van de film om deze thuis te bekijken, een vragenlijst die na het bekijken van de film ingevuld diende te worden (nameting) en een antwoordenveloppe om de vragenlijst van de nameting portovrij naar TNO te sturen.

De arts of verpleegkundige hoefden tijdens het consult geen tijd voor het onderzoek in te ruimen. Wel werden zij op de hoogte gebracht van de website van de film, om zo eventuele vragen bij een later consult te kunnen beantwoorden.

Ouders die wel een voormeting hadden ingevuld, maar geen nameting hadden teruggestuurd, werden telefo- nisch of per e-mail benaderd met de vraag of zij de voorlichtingsfilm hadden bekeken. De precieze hoeveelheid tijd tussen de voor- en de nameting is onbekend sommige ouders bekeken de film mogelijk dezelfde dag en vulden aansluitend de nameting in, andere ouders deden dat mogelijk op een andere dag - maar bedroeg maximaal 6 weken, de duur van de dataverzameling. In de voormeting werd gevraagd naar achtergrondgegevens, zoals geboorteland van de moeder, opleidingsniveau van de moeder, aantal kinderen en de leeftijd van de kinderen. Naar kennis over de adviezen van het Ivoren Kruis werd zowel in de voor- als de nameting gevraagd. Het opleidingsniveau van de moeder werd geclassificeerd in hoog (afgeronde opleiding havo, atheneum, gymnasium, vwo, hbo of universiteit) en laag (geen opleiding, lagere school of basisschool, lbo/vbo, mavo en mbo). Dit is een veelgebruikte indeling binnen tandheelkundig epidemiologisch onderzoek, gezien het evidente verschil in mondgezondheid tussen deze twee opleidingsniveaus. ${ }^{12}$ Een totale kennisscore werd berekend door het aantal vragen dat goed werd beantwoord bij elkaar op te tellen De maximaal te behalen score was 15. Een gepaarde t-toets werd uitgevoerd om de kennisscore van de vooren nameting met elkaar te vergelijken.

\section{Resultaten}

Van de 102 gevraagde ouders/verzorgers stemden er 95 in met deelname $(93 \%)$. De non-responders gaven als reden op geen tijd of zin te hebben $(n=2)$, geen computer te hebben $(n=1)$, of geen Nederlands te spreken $(n=2)$. Twee deelnemers gaven aan thuis de vragenlijst te invullen, maar hebben dat niet gedaan.

Van de 95 deelnemers had $49 \%$ de vragenlijst van de voor- en de nameting ingevuld en deze laatste ook teruggestuurd $(n=47)$. De vragenlijsten werden in $96 \%$ van de gevallen door de moeder ingevuld.

Op de vraag in de voormeting waar de moeder van het kind geboren was, antwoordde $96 \%$ van de 95 respondenten dat dit in Nederland was; $51 \%$ van de moeders was hoogopgeleid. 48 respondenten vulden alleen de voormeting in; in $85 \%$ van de gevallen deed de moeder dit; $40 \%$ van de moeders was hoogopgeleid.

Vier van de 48 personen die de nameting niet hadden teruggestuurd, bleken bij nabellen de film wel te hebben bekeken. Dit betekent dat de film 52 van de 102 personen heeft bereikt (51\%).

Tabel 1 toont de resultaten met betrekking tot de kennis die de ouders hadden over het kindergebit en de verzorging daarvan, voor en na het bekijken van de voorlichtingsfilm.

Een aantal vragen was opgebouwd uit twee stappen, zoals bij vraag 1 'Op welke leeftijd krijgt een baby over het algemeen de eerste tand?' Wanneer men dit wist of dacht te weten, werd het aantal maanden ingevuld. Wanneer men het antwoord niet wist, werd 'weet niet' 
r.ibi i Percentage respondenten met correcte antwoorden op de kennisvragen van de groep die zowel de voor-als de nameting ( $n=47$ ) als de groep die alleen de voormeting invulde $(n=48)$

\begin{tabular}{|c|c|c|c|}
\hline \multirow[t]{2}{*}{ viciag (ontwoond) } & \multirow{2}{*}{$\begin{array}{l}\text { vile'tin } \\
\text { voometrigs } \\
\text { ingleveld }\end{array}$} & \multicolumn{2}{|c|}{$\begin{array}{l}\text { noor-ch lanieting } \\
\text { megevel }\end{array}$} \\
\hline & & voorinering & nometing \\
\hline 1. Op welke leeftijd krijgt een baby over het algemeen de eerste tand? ( 6 maanden) & $44 \%$ & $53 \%$ & $100 \%$ \\
\hline 2. Op welke leeftijd is het melkgebit meestal compleet? $(2,5$ jaar $)$ & $9 \%$ & $21 \%$ & $100 \%$ \\
\hline $\begin{array}{l}\text { 3. Wanneer moet er worden begonnen met tandenpoetsen? (zodra het kind de } \\
\text { eerste tand heeft) }\end{array}$ & $92 \%$ & $98 \%$ & $100 \%$ \\
\hline $\begin{array}{l}\text { 4. Hoe vaak moeten de tanden van een kind (leeftijd 2-5 jaar) worden gepoetst? } \\
\text { (twee keer per dag) }\end{array}$ & $79 \%$ & $85 \%$ & $96 \%$ \\
\hline $\begin{array}{l}\text { 5. Als de tanden van een kind (leeftijd 2-5 jaar) worden gepoetst dan kan je dat het } \\
\text { beste doen met... (fluoridetandpasta voor peuters) }\end{array}$ & $83 \%$ & $79 \%$ & $98 \%$ \\
\hline $\begin{array}{l}\text { 6. Als de tanden van kind ouder dan } 5 \text { jaar worden gepoetst dan kan je dat het } \\
\text { beste doen met.... (fluoridetandpasta voor volwassenen) }\end{array}$ & $40 \%$ & $47 \%$ & $98 \%$ \\
\hline $\begin{array}{l}\text { 7. Tot welke leeftijd van het kind moet een volwassene het gebit van het kind } \\
\text { napoetsen? (tot het kind ongeveer } 10 \text { jaar oud is) }\end{array}$ & $15 \%$ & $9 \%$ & $96 \%$ \\
\hline 8. Moet een kind met water spoelen na het poetsen? (nee) & $42 \%$ & $47 \%$ & $91 \%$ \\
\hline $\begin{array}{l}\text { 9. Hoe vaak per dag mag een kind maximaal iets eten, drinken of snoepen? (maxi- } \\
\text { maal } 7 \text { keer per dag) }\end{array}$ & $17 \%$ & $20 \%$ & $98 \%$ \\
\hline 10. Is water mogelijk schadelijk voor het melkgebit? (nee) & $100 \%$ & $100 \%$ & $98 \%$ \\
\hline 11. Is melk mogelijk schadelijk voor het melkgebit? (melk is schadelijk) & $19 \%$ & $13 \%$ & $77 \%$ \\
\hline 12. Is vruchtensap mogelijk schadelijk voor het melkgebit? (vruchtensap is schadelijk) & $88 \%$ & $94 \%$ & $92 \%$ \\
\hline $\begin{array}{l}\text { 13. Is frisdrank light mogelijk schadelijk voor het melkgebit? (light frisdrank is } \\
\text { schadelijk) }\end{array}$ & $88 \%$ & $92 \%$ & $94 \%$ \\
\hline $\begin{array}{l}\text { 14. Wat is beter voor het melkgebit: drinken uit een fles of uit een beker? (uit een } \\
\text { beker) }\end{array}$ & $85 \%$ & $96 \%$ & $100 \%$ \\
\hline $\begin{array}{l}\text { 15. Op welke leeftijd moet een kind voor het eerst naar de tandarts voor controle? } \\
\text { ( } 2 \text { jaar) }\end{array}$ & $36 \%$ & $45 \%$ & $100 \%$ \\
\hline
\end{tabular}

De derde en vierde kolom tonen het effect van de film op het kennisniveau, doordat de scores op de voormeting (kolom 3) kunnen worden vergeleken met die op de nameting (kolom 4). De responsvertekening is te bepalen door de tweede kolom, met data over de ouders die alleen de voormeting hadden ingevuld $(n=48)$, te vergelijken met de derde kolom.

ingevuld en werd dit als 'niet correct' beoordeeld. Ouders die zowel de voor- als de nameting hadden ingevuld, hadden bij de voormeting een totale kennisscore van 8,6 (SD 1,8); bij de nameting was deze score 14,2 (SD $1,3)$. Dit verschil was significant $(p<0,001)$. De totale kennisscore was sterk toegenomen. Ouders die alleen de voormeting hadden ingevuld, hadden een gemiddelde kennisscore van 8,1 (SD 2,2). Deze score verschilde niet significant van de totale kennisscore van ouders die zowel de voor-als de nameting hadden ingevuld. Verder valt op dat:

- de kennis over het gebruik van peutertandpasta of tandpasta voor volwassenen na het zien van de film was toegenomen;
- slechts weinig respondenten van tevoren wisten dat het kindergebit tot de leeftijd van 10 jaar nagepoetst dient te worden; na het bekijken van de film wist nagenoeg iedereen dat;

" de kennis over het aantal eet-, drink- en snoepmomenten toenam;

- de kennis over de aanbevolen leeftijd om voor het eerst naar de tandarts te gaan toenam.

Bij de nameting werden vragen gesteld over de vorm en de inhoud van de voorlichtingsfilm. Van de 48 respondenten hadden er 47 de film helemaal bekeken. Alle respondenten vonden de film informatief en duidelijk. $79 \%$ vond de film goed van lengte, $21 \%$ vond de film te lang. 


\section{Discussie}

In dit onderzoek is een eerste verkenning uitgevoerd naar de effectiviteit van een web-based voorlichtingsfilm, aangeboden op het CB. De vraagstelling was of deze aanpak een bijdrage kan leveren aan het kennisniveau van ouders met betrekking tot de mondgezondheid van hun kinderen. Het onderzoek werd uitgevoerd als lokale pilotstudie: het lag niet in de bedoeling de resultaten te generaliseren naar de Nederlandse populatie. De ouders die zowel de voor- als de nameting hadden ingevuld, leken wat achtergrondkenmerken betreft niet veel te verschillen van de ouders die alleen de voormeting hadden ingevuld.

De antwoorden op de vragen bij de voormeting waren mogelijk gerelateerd aan eigen ervaring. In de nameting leken deze antwoorden gebaseerd te zijn op toegenomen kennis door het zien van de film.

In de inleiding werd opgemerkt dat kennis een noodzakelijke voorwaarde is voor het uitvoeren van gewenst gedrag. In die zin zijn de resultaten van onze studie zeer hoopgevend. Na het zien van de film, in de nameting, was de kennis bijna perfect. Als het veronderstelde modelingeffect werkelijk optreedt - ouders gaan het gewenste gedrag uitvoeren doordat het in de film is voorgedaan - zijn deze resultaten ook wat dat betreft veelbelovend. De nameting vond echter zeer kort na het zien van de film plaats. In deze pilotstudy is niet onderzocht in hoeverre de kennis en het gedrag op langere termijn beklijven. Dit zullen onderzoeksvragen zijn van de vervolgstudie.

Voorlichting mondgezondheid valt momenteel niet onder het uniforme deel van het basistakenpakket en wordt dus incidenteel gegeven. Door gebruik te maken van de voorlichtingsfilm is het bereik $51 \%$. Het zou een strategie kunnen worden van de jeugdgezondheidszorg om bij een volgend consult na te vragen of de film bekeken is. Als dat niet het geval is, kan de informatie alsnog door de arts of verpleegkundige worden gegeven. Gezien de positieve resultaten lijkt het gerechtvaardigd de voorlichtingsfilm op grotere schaal te testen. Daarbij dient aandacht te worden geschonken aan een verbetering van het bereik, bijvoorbeeld door ouders meer dan eens op het bestaan van de film te wijzen.

De pilotstudie is uitgevoerd in Zeeland. De respondenten waren nagenoeg allemaal van autochtone afkomst en ruim de helft was hoogopgeleid. Deze kenmerken verschillen van die van de algemene Nederlandse populatie in ongeveer dezelfde leeftijdsgroep (20-40 jaar), van wie circa $27 \%$ van allochtone afkomst is en $30 \%$ hoogopgeleid (CBS Statline, 01-07-2010). De mondgezondheid van hogere sociaal-economische groepen is beter dan die van lagere sociaal-economische groepen. ${ }^{10}$ In principe zou er daarom bij de groep met een laag opleidingsniveau nog meer 'winst' te behalen moeten zijn. In een vervolgstudie, ook uit te voeren in gemeenten buiten Zeeland, zal worden onderzocht of de film ook deze doel- groepen bereikt en daar dezelfde effecten heeft. Overwogen is om de voorlichtingsfilm in de wacht-/ kleedruimte van het $C B$ te vertonen. Het is echter onbekend hoeveel CB's hiervoor geschikte apparatuur hebben. Verder geeft het waarschijnlijk te veel onrust in deze ruimte en ouders zullen vaak pas halverwege in de film terechtkomen of er halverwege weer uitstappen, omdat zij aan de beurt zijn voor hun consult. Daarom is besloten om van dit plan af te zien.

Mocht uit een uitgebreidere studie blijken dat de film de gewenste effecten heeft en wordt vervolgens landelijke invoering overwogen, dan kan het een idee zijn om op het kaartje waarop de link naar de website staat, enkele vragen te zetten. Het niet kunnen beantwoorden van deze vragen stimuleert mogelijk om de film te gaan bekijken. Dit zal in een vervolgstudie worden onderzocht.

Tot slot

Informatie verstrekken over een onderwerp uit een maatwerkdeel (bijvoorbeeld mondzorg) door het meegeven van een kaartje met een link naar een voorlichtingsfilm kan worden uitgebreid naar andere maatwerkonderwerpen. Dit zou betekenen dat bezoekers van een $C B$ het op den duur heel gewoon zullen gaan vinden om bij elk consult een link mee te krijgen naar een voorlichtingsfilm die van toepassing is op de ontwikkelingsfase waarin hun kind zich bevindt.

Op deze manier zouden dan de onderwerpen die gewoonlijk tijdens de consulten niet of nauwelijks aan bod komen, toch onder de aandacht kunnen worden gebracht.

\section{Literatuur}

1. Schuller AA, Bruers JMM, Dam BAFM van, Poorterman JHG, Gerardu VAM, Truin GJ. De restauratieve verzorgingsgraad bij de jeugd. Deel 1: Kindfactoren. Ned Tijdschr Tandheelkd. 2009;116:347-53.

¿ Verrips GHW, Schuller AA, Gerardu VAM. Behandeling van angstige volwassen patiënten in Centra voor Bijzondere Tandheelkunde. Bilthoven: TNO Kwaliteit van Leven; 2009.

3. www.ivorenkruis.nl.

6. Signalement mondzorg 2010. Diemen: CVZ; 2010.

5 Nationaal Kompas Volksgezondheid, versie 3.22, 24 juni 2010. Bilthoven: RIVM; 2010.

6. Alsada LH. Development and testing of an audio-visual aid for improvement of infant oral health through primary caregiver education. MSc Thesis. Toronto: University of Toronto; 2004.

\% Plutzer K, Spencer AJ. Efficacy of an oral health promotion intervention in the prevention of early childhood caries, Community Dent Oral Epidemiol, 2008;36:335-46.

8 Gussy MG, Waters EB, Riggs EM, Lo SK, Kilpatrick NM. Parental knowledge, beliefs and behaviours for oral health of toddlers residing in rural Victoria. Austral Dent J. 2008;53:52-60.

5. Weinstein P, Harrison R, Benton T. Motivating mothers to prevent caries.J Am Dent Assoc. 2006;137(6):789-93.

10. McAuley E. Modeling and self-efficacy: a test of Bandura's model. J Sport Psychol. 1985;7(3):283-95. 